HIMALAYA, the Journal of the HIMALAYA Himalayan Studies

Volume 17

Number 2 Himalayan Research Bulletin:

Article 13

Solukhumbu and the Sherpa

1997

\title{
High Altitude Mountaineering, Cash Economy, and the Sherpa
}

Robert Miller

University of Wisconsin, Madison

Follow this and additional works at: https://digitalcommons.macalester.edu/himalaya

\section{Recommended Citation}

Miller, Robert. 1997. High Altitude Mountaineering, Cash Economy, and the Sherpa. HIMALAYA 17(2).

Available at: https://digitalcommons.macalester.edu/himalaya/vol17/iss2/13

This Research Article is brought to you for free and open access by the DigitalCommons@Macalester College at DigitalCommons@Macalester College. It has been accepted for inclusion in HIMALAYA, the Journal of the Association for Nepal and Himalayan Studies by an authorized administrator of DigitalCommons@Macalester College. For more information, please contact scholarpub@macalester.edu. 


\title{
High Altitude Mountaineering, Cash Economy, and the Sherpa
}

\author{
Robert Miller ${ }^{1}$
}

This [Khumbu] is the home of the great Sherpas who have made themselves famous from the Karakoram to Sikkim, contributing all their strength and all their intelligence to the exploration of the great Asiatic chain. Without them, the approach to the few mountains that have been conquered would never have been possible. All the Europeans who have come to the region owe them a heavy debt.

Thus wrote Rene Dittert in Forerunners to Everest. ${ }^{2}$ Such tributes to the Sherpa of North-East Nepal and Darjeeling district, West Bengal are not unusual in the literature of Himalayan mountaineering. The reports of the early Everest expeditions, F. Smythe's Kanchenjunga Adventure, ${ }^{3}$ and later reports of other expeditions attest to the ability of the Sherpa; indeed the writers are lavish with praise. Why did this group of Tibetan-derived inhabitants of the Himalayan foothills become the virtually uncontested mainstay of Himalayan expeditions? And what effect has this specialization on portering, now practically synonomous with the term Sherpa, had upon the Sherpa way of life?

Sherpas were first employed as porters in 1909 by Kelas, father of Himalayan climbing. ${ }^{4}$ Initially Sherpas and Tibetans were considered to be about equally capable, but by the time of the first Everest Expeditions, the Sherpa dominance in high-altitude work had been established. During the 1922 assault

It was rather amusing to see the superior airs which the Sherpas invariably gave themselves in traveling through Tibet. They considered Tibetans

1 Robert Miller, who died in April of 1994, was in the Department of Anthropology, University of Wisconsin, Madison. $H R B$ is grateful to Beatrice Miller for encouraging us to reprint this article, and to Human Organization for permitting it.

2 Rene Dittert, Gabriel Chevally and Raymond Lambert, Forerunners to Everest, London, 1954.

3 Frank Smythe, The Kanchenjunga Adventure, London, 1946.

4 Ibid., p. 21. undoubtedly jangli (wild) and treated them very much from the point of view that a clever Londoner does the simplest form of yokel when he appears in London. At any rate, they backed themselves heavily to best the Tibetans. It was a pretty good race, but finally they came well out on top; in fact ... all but one who reached 25,000 feet and over were Sherpas...5

Certainly something other than the nature of the work and the pay entered into the Sherpa attraction to portering. Especially during the earlier expeditions, the work was mostly a continuation of their traditional load-carrying in Khumbu and across passes into Tibet. The hardiness and carrying ability of the Sherpa impressed all expeditions:

As carriers they are unsurpassed, for they are brought up to it from their youth. When quite small children they learn to carry loads, fetching and carrying water and grain for the upkeep of homes... That these people think little or nothing of traversing [the 19,000 foot Nangpa pass] is clearly shown by the fact that there is a continuos traffic across it for five months of the year, and that among the travelers are frequently seen women carrying their babies and small children on their backs. ${ }^{6}$

We passed two ... women who were returning from Those to Namche; they had been to buy rice and each was carrying back about 140 pounds; . . .

5 C. G. Bruce et al., The Assault on Mount Everest, 1922, 2nd printing, London, 1924, p. 63.

6 E. F. Norton et al., The Fight for Everest, 1924, London, 1925, p. 59. 
on the main Tibetan route through Namche Bazaar to Tingni Dzong ... Whole families were on the move, the children of 12 years carrying from 65 to 85 pounds, and the men up to 170 pounds or more!

But in addition to load-carrying ability, the twin elements of competition and prestige entered into the Sherpa portering, as evidenced by the race with the Tibetans and in the fact that volunteers were never lacking despite occasional mishaps to comrades or relatives. Many volunteers could have had easier and remunerative employment in and around Darjeeling during the tourist season, without the hazards entailed by climbing. The prestige element, however, entered into their willingness to serve. The "Tiger" badge, awarded to those who exceeded 25,000 feet during a climb, was a precious symbol of ability. Whatever the primary factor in their drive; more and more Sherpas became involved in climbing. The participation in expeditions was not limited to Sherpa living in Darjeeling, even though the early expeditions recruited there. As early as 1922, Sherpa from Khumbu in Nepal were crossing the passes to join expeditions in Tibet. By 1933, a small but regular stream of Sherpas was filtering down to Darjeeling, drawn by the prospect of jobs as porters to new expeditions. Such infiltration stimulated the European trend to the Sherpa porter--it was less necessary to follow the suggestion made by Smythe on the basis of his 1930 experience:

Expeditions starting from Darjeeling should give long notice of their intended date of departure, in order that coolies may have time to come in from remote villages... ${ }^{8}$

By 1933, high-altitude portering had become a Sherpa profession. The growth of the Darjeeling Sherpa community attests to the drawing power of this specialized occupation: in 1901 there were 3,450 Sherpa in the Darjeeling District; in 1931 the number had increased to 5,295 , in 1940 to 6,929 and in 1951 to 8,998. Part of the increase was due to births among already resident Darjeeling Sherpa, part was a result of migration from Nepal. Not all who came managed to obtain support from the expeditions-some entered trade, others raised garden crops, still others engaged in local portering-but the lure of the expedition seems to have been operative in most instances.

7 Dittert, op. cit., pp. 33, 36.

8 Simythe, op. cit., p 323.

\section{The Khumbu Background ${ }^{9}$}

What effect did this Sherpa portering have upon the Sherpa homeland? Before this question can be answered we must examine the situation there prior to the 1930's.

Life in Khumbu was hard. A rigorous existence was supported by the cultivation of wheat, potatoes, and barley, some maize and radishes, and by yak-herding, supplemented by traditional trade with Tibet. The altitudes at which cultivation and herding were practiced $(10,000+$ feet $)$ intensified the difficulties of wrestling a living. Items such as utensils and rice were imported from lowland Nepal, salt from Tibet via the high passes. There were a few rich families, but most Khumbuwa (the local designation for Sherpa resident in Khumbu) were tenants working the lands of absentee landlords. Many were in debt to richer families or to the Buddhist monasteries in the region. Added to the local indebtedness, the Nepalese government assessed an annual tax. This tax was collected by two individuals called the Lumbardar and the Chokidar (village watchman). Initially, these two collectors had been appointed by the Nepalese ruler at the suggestion of a monk from the more "Nepalized" Sherpa of Solu (a group living at a lower altitude and exhibiting a combination of Sherpa-Tibetan and Nepalese cultural elements). Once appointed, the offices became hereditary and remained in Sola hands.

The two hereditary officials, and their Sola supporters, had considerable power. Any Khumbuwa who had gone to India, particularly to Darjeeling, and had worked as rickshaw puller, bearer (attendant) or cook to Europeans, could not reenter his village until he had been "purified." He had to remain outside his village and present gifts (usually money) to the Lumbardar and Chokidar, who would then call Lamas (Buddhist monks) to "cleanse" the returnee. This concept of pollution through contact with foreigners was alien to the Sherpa and Tibetan ideology, and indicates the penetration of Nepali-Hindu caste ideas into Sola culture. The Khumbuwa, however, were at this time in no position to defy the arbitrary regulations imposed upon them.

The increasing flow of Sherpas to Darjeeling in the 1930's, however, made great inroads on this tight system. The control by the Lumbardar and Chokidar was broken. As more young Khumbuwa returned from Darjeeling, they refused to pay to reenter their village and scoffed at the idea of impurity. Since relatively large numbers of young men were moving back and forth frequently, involving many village families at once, the two officials could not enforce their demands.

9 This section is based on field notes. Main informants were Lhakpa Tenzing, born in Khumbu, who left in the $1930^{\prime} \mathrm{s}$, returned in the 1940 's, and who had traveled extensively on Government service in Ladakh, Sinkiang and Nepal. Others were Tenzing Norgay, Gyaljen Sirdar (a former "Tiger" and a lama) and our gracious servant, Lhakpa Sherpani. 
The system of purification-payment lacked government sanction and when even the lamas and some Sola men began to join the climbing expeditions as porters, the system gave way.

Mountaineering brought significant economic changes to Khumbu. ${ }^{10}$ The young porters represented a secondary source of income to the families at home, and there was less need to borrow money from the few rich families. Few men remained to work the land of the wealthier landholders, who in consequence lost one of their lines of control over the less favored population. Fewer poor families were forced to mortgage their small holdings to the rich, and the reduction of many families to tenant-status was slowed. In short, tenants and debtors became fewer, and the preeminent economic role of the rich declined. The family climber became an economic mainstay

The young Sherpa who. stayed in Darjeeling were impressed by the modern conveniences which they saw and used. Many arranged to bring their Khumbuwa relatives and parents to Darjeeling and to acquaint them with concepts of sanitation, of Western standards of dress and coiffure and other Western ideas. Others participating in the expeditions reestablished kinship lies which had been sundered, strengthening the link between Darjeeling and Khumbu Sherpa. For example, a famous Tiger, Lhakpa Chedi, who joined the 1924 Everest Expedition was

A native-born of Darjeeling, [who] had never been to the hub of the Sherpa universe, the large Sola-Khumbu settlements at the head of the Dudh Kosi in Nepal, although his father hailed from that place."

\section{And thirty years later}

". . Tenzing unexpectedly met an elder sister whom he had not seen for twenty years . . " 12

Others deliberately used the expedition as a paid return to their homes:

soon a woman came to stop us . . she was the mother of one of our porters and had come to invite us to her home. In truth, we were far from suspecting he was a Sherpa: he was young, with long hair and a soft girlish face. The mother thanked us for having brought her son back, but her thanks were undeserved, for we knew nothing of the family's affairs. The boy had escaped from the paternal home and had got himself engaged as a porter in order to return there, so that we were present at the warm welcome to the prodigal son. ${ }^{13}$

10 For a recent study of Khumbu Sherpa, see Christof von Fürer-Haimendorf, The Sherpas, London, 1964.

11 Norton, op. cit., p. 18.

12 Dittert, op. cit., p. 32.

13 Ibid., p. 47.
A final effect of the increasing participation of young Khumbuwa in expeditions was the expansion of the major Khumbu settlement, Namche Bazaar, into an international market; Namche became a center for the resale of used mountaineering equipment and was patronized by even smaller European expeditions. With the apparently indefinite shift of expeditions to the Nepalese route (rather than moving through Tibet as some earlier expeditions had been able to do) Namche may retain this new role.

The effects of mountaineering on the Khumbu homeland have been dramatic. A transition from essentially subsistence economy to more and more reliance upon supplementary cash income, together with less reliance upon land and herds has involved more and more Sherpa families. But there is still some resistance to the new wave. Although the majority of the youth are anxious to bring changes or to leave, parents sometimes look upon mountaineering employment as a mixed blessing:

Young Mingma ... had made up his mind to travel with the party and see the big world outside Khumbu. But his mother not unnaturally thought otherwise. Arriving on the scene early on the morning of their departure from Namche, she railed at the would-be abductors of her child. "You have taken my husband," she said, "now you would snatch my son away from me too. Mingma, come here!," and the weeping fourteen-year-old was led unwillingly back to his home. ${ }^{14}$

The youth, however, are not easily convinced of the necessity to stay:

Ang Tsering, aged seventeen, .... was more cunning when his parent also appeared on the scene with the same intentions as Mingma's mommy. He persuaded her to let him go with the party as far as Ghat, one march distant down the valley .... She was guileless enough to agree with this entreaty. Needless to say, Ang Tsering is now in Darjeeling with all the other boys. ${ }^{15}$

\section{Darjeeling Sherpa}

While there have been telling effects upon the Sherpa homeland, the Darjeeling Sherpa have been most marked by mountaineering. Sherpa have become a highly specialized, technically trained group. Contrast the statement by Norton, writing about the 1924 Everest Expedition, with that of Dittert, the Swiss climber:

Herein lies a moral . . . . These men (Sherpa) are not really all-around mountaineers; they have little knowledge of snow and ice, and are as subject as

14 Sir John Hunt, The Ascent of Everest, London, 1953, p. 223.

15 Ibid., p. 224. 
other inexperienced amateurs to sudden loss of nerve if something goes wrong ... 16

Without them [Sherpas] no one could go far. I don't know where they get their incredible resources and reserves from .... When they can do no more, they just fall. ${ }^{17}$

These two statements sum up almost three decades of Sherpa portering and the creation of a tradition. The element of prestige has become extremely important to the Darjeeling Sherpa. Sherpa specialization has been recognized by the establishment of the Himalayan Mountaineering Institute under the auspices of the Indian Government, with a new branch in Mandi Kulu (Punjab). A staff of Sherpas trained by expeditions and through special instruction in Switzerland has been recruited to the Institute. The Himalayan Club, long the arbiter of which Sherpa should be employed by an expedition, has recommended that application for porters be made directly to the Sherpa Sardars (leaders), because

it was never the intention of the Club that the Honorary Local Secretary in Darjeeling should permanently become responsible for organizing Sherpa porters for expeditions, and . . . there are now Sherpa Sardars able themselves to accept this responsibility . . 18

Under the leadership of Tenzing Norgay, the Sherpa Buddhist Association of Darjeeling has become the Sherpa Climbers' Association, a mutual aid organization. Tenzing has become the most prominent Sherpa in Darjeeling, but his exploits have also reminded many persons of the older climbers. The West Bengal District Handbook for Darjeeling (part of the publications of the 1951 Census of India) devotes considerable space to reviewing the participation of Sherpas in mountaineering and picks out for mention the various Tenzings of earlier days.

But this specialization and recognition have not been unmixed blessings for the Darjeeling Sherpa. Some British climbers gradually came to feel that the Sherpa had been too highly praised, and were forgetting their place (Personal discussion, Darjeeling). At least one Indian newsman echoed this idea in the press:

I really think we should define the position of the porters before any further expedition is allowed on the Himalayas . . A Mountaineer is a mountaineer and a Sherpa is a Sherpa, and the sooner we begin to recognize the very real distinction, the better. I want my country, India, to make its mark in Himalayan climbing, and I would like Sherpas, whose country is Nepal, to be associated with the effort. . . I would like India to have credit (if successful) exclusively, without the

16 Norton, op. cit.

17 Dittert, op. cit.

18 H. W. Tobin (ed.), The Himalayan Journal, XVIII, Calcutta (1954). charming Sherpas asking for a share in it beyond the wages they have been paid .. . ${ }^{19}$

Indisputably, the almost exclusive reliance upon Sherpas in recent years has created among many of them the feeling of indispensability. As a result, the male Darjeeling Sherpas have become dependent upon an exceedingly unstable occupation, and their livelihood is subject to control by the vagaries of enthusiasm and financial support for mountaineering abroad. Through the establishment of the Himalayan Mountaineering Institute, the Indian Government has astutely attempted to make it a more predictable form of livelihood for trained climbers. But a small group of Sherpa tended tc price themselves out of the market. Formerly the Sherpa porter worked for a stipulated wage during the expedition and expected little else except some sort of gratuity-bakshish-when it was over. Now, the porter expects sick-and-death benefits for climbers or their survivors, equipment equal to that of the sahibs (the European or Indian Climbers), special European food at high altitudes and, since the example of Tenzing, some are even interested in a chance tc participate in the actual assault upon the peak.

In all these stipulations, the most demanding Sherpa make little or no distinction between the massive government or institutionally supported expeditions and the small private parties who plan to climb on a shoestring. Because of this attitude, a certain antiSherpa undercurrent has become apparent among some climbers since the Everest conquest. There have been some attempts to train other porters, notably the Gharwalis of the western Himalaya, but such porters have not successfully challenged the position of the Sherpa. Among the Sherpa themselves, there has been an effort to bring the realities of the situation home tc the less farsighted.

Another attempt to bypass Darjeeling Sherpa is the practice of hiring local porters in Khumbu. Ultimately. however, this is self-defeating. The truly experienced high-altitude workers usually find their way to Darjeeling, as has been noted earlier. Once in Darjeeling, they are assimilated to the Sherpa community, and become equally spoiled from the climbers' point of view. The gap between the Darjeeling porter and the unspoiled Khumbu porter continues to be widened through the Governmenl Training Institute, the Swiss experiences of Institute men, and the time limits on expeditions which requires an experienced group to perform with a reasonable precision if successes are to be registered. The massive investments in an expedition cannot be risked on raw material.

Conversely, the Darjeeling Sherpa have become very dependent upon the continuation of climbing expeditions. Should there be a decline in funds for the

19 Cassius, "It Depends," The Hindustan Standard, (May 18, 1953), Calcutta. 
Institute, or a Nepalese government decision to close Nepal once more to climbers, the whole structure could collapse (or at the least be crippled). The Sherpa then would be in the same position as were the Tibetan rickshaw-pullers when the motor car replaced the rickshaw in Darjeeling.

\section{General Effects}

Two pictures have been drawn: on the one hand the Sherpa home base in Khumbu and on the other, the specialized picture of the Darjeeling Sherpa. Socially and economically mountaineering has brought disturbing changes to both. What other effects has mountaineering had on Sherpa life? Other than training in climbing, involvement in wage-labor and prestige, what have the Sherpa obtained from the mountaineers?

One might begin with exotic bits of knowledge now commanded by Sherpas in both areas. Methods of operating equipment such as portable cook-stoves, oxygen equipment, motion picture and still cameras are know. Some have become quite proficient at photography and continue to take pictures for pleasure. On the Swiss expedition (1952), some learned to construct an igloo! An outlook broadened by extensive travel is a side-result of participation in mountaineering. Some Sherpa have traveled to many parts of India, others have traveled as far as to Switzerland and England. Those who have been in the business for many years usually can speak numerous dialects of Indian and Nepalese languages and have noticed the differences in ways of life among the peoples of different areas - and have selected elements or ideas from these experiences for introduction at home. Almost all have developed a fondness for European camping equipment such as tents, sleeping bags, boots, highaltitude down clothing. Some keep their equipment and help supply themselves for climbs, but many tend to sell the items given to them and to demand more on each climb. They thus help to spread the use of such items as noted above beyond the immediate Sherpa community. It is obvious that these benefits are of dubious value in Khumbu-tastes, skills and needs have been created through mountaineering, and only mountaineering can continue to satisfy them, while the Sherpa is unable to maintain a realistic perspective on the whole process.

Various expeditions had helped build up the spirit of indispensability in the Sherpa porter as part of the psychological conditioning for successful performance. Now some climbers tell the Sherpa that this was not really meant to be taken quite so seriously. Naturally there is confusion. For the most part, the British have liked the Sherpa but have resisted the idea that Sherpa porters might be treated as equal partners in the climb, with opportunities to take part in the actual ascents. On the other hand, the Swiss and the French have tended to consider the Sherpa as potential Swiss guides and have emphasized the joint effort of all in a successful climb. Gabriel Chevally summed up the Swiss attitude in this way:

We did well to treat them as brothers. They didn't take long to understand that we were then friends. This is what made it possible for them to put up, between the sixteen of them, one of the biggest efforts ever made in the Himalaya. ${ }^{20}$

Perhaps some of the difficulties which certain English climbers encountered with the Sherpa is related to their lack of understanding of Sherpa attitudes. The Sherpa was not servile, and tended to take on a job out of interest, loyalty, a sense of comradeship, perhaps even of adventure. The early English climbers despite their admiration for Sherpa toughness and ability, treated the Sherpa as secondary members of the expedition, as hired laborers whose tasks, though arduous, were paid for. The admiration was real, but it was primarily extended to the exception, the outstanding porter. Even in 1953 this attitude was not entirely lacking:

But it would be unwise indeed to judge the Sherpa race altogether by the example of Tenzing and his splendid kind. The chief characteristic that is likely to strike an observer meeting the Sherpa on his home ground away from the influence of Europeans and the call of the high mountains to duty and fidelity, is his rock-like insensibility...

Their shuttered and anachronistic way of life has given the Sherpas a sturdy independence; it has also perhaps fostered a certain grotesque heartiness that seems especially assertive, no doubt because of an innate sense of self-protection, when there are Europeans in the offing. ${ }^{21}$

Rarely was it thought that even the exception might aspire to climb for the sake of climbing. It must be emphasized that this attitude was by no means shared by all British climbers, although it seems to coincide with the opinion of a large segment. On many climbs, however, the European has found much in common with the Sherpa; love of mountains, respect for ability, enthusiasm for nature in the rough, a willingness to try new foods and other items. A Sherpa and one or another sahib could develop real comradeship. The Sherpa sense of humor and type of humor is close enough to that of the European so that mutual enjoyment of "gags" is possible. Thus, those Europeans who accepted the Sherpa as individuals in a joint enterprise found that an almost mystic closeness could develop between them, even surmounting language barriers

20 Dittert, op. cit.

21 Census, West Bengal: District Handbook, Darjeeling, A. Mitra (ed. and compiler), Alipore, West Bengal, 1953. 


\section{Reverse Effects}

While most of the influences of mountaineering have flowed from European to Sherpa, particularly in regard to material items, there has been some minor reverse influence. Europeans soon fell into the habit of obtaining a blessing ceremony for the expedition at one of the major Buddhist monasteries in Khumbu; the Swiss expedition discovered that

the reindeer-skin high altitude boots inspired by the footwear worn for a long time by people obliged to struggle against the cold-Eskimos, Laplanders and Tibetans ...

were a great improvement over the standard European boots. "Sherpa" has been adopted for the name of an high-altitude fighting plane in Britain; "Sherpa" linings grace cold-weather coats in the United States; and children (with their parents) were exhorted not too long ago, on television, to eat Rice Krispies, because the food of the "brave Sherpas who climbed Mt. Everest" was rice. The reverse effects in a sense, can be seen to extend to the interest aroused in the "Abominable Snowman" tales, with the subsequent financing of numerous expeditions to find this creature.

\section{Conclusions}

Is this whole picture unique? In one sense, it is a rare example of a small and relatively esoteric aspect of Western culture which has effected numerous changes in the life of a whole group. We have virtually no comparable data from the areas in which non-Western groups have participated in mountaineering, for example the Andes, Africa, the Pamirs. An interesting comparison might be made to the effects of mountaineering on Swiss economy, particularly in the early stages of Swiss participation in the endeavors. Questions might be raised on another level of analysis, for example, the effects of service in British military activities by Gurkhas, with similar aspects of movement to new areas, acquaintance with new clothing, foodstuffs, and equipment. But such comparisons would perhaps give us further data on the process of culture change per se. It would not explain the particular Sherpa success in and affinity for mountaineering.
Actually the Sherpa success may lie in his cultura background, and may not be duplicated in other cases The traditional training at load-carrying as a child, thi willingness to struggle against adverse conditions, thi attraction for the mountains, all fit the Sherpa for hi new position and have favored the process of change it a certain direction. Tenzing himself expresses i succinctly:

We came originally from the mountains. Now we go back to the mountains. But it is in a very different way that we go to them, and between expeditions our lives are different too. ${ }^{22}$

The relatively long, easy and intermittent contact o Sherpas with Europeans in this kind of enterprise may have been a critical factor in the development of changt without expensive disruption. But the new values tc which the Sherpa have been educated will not as easily be lost. Again, Tenzing expresses it well:

We are a people in the midst of change, and what will happen in the future is hard to say. But so far, though we have left our homeland, we have stayed pretty much together, and there has not been much intermarriage with outsiders. ${ }^{23}$

From the standpoint of culture contact and culture change, the specialized Sherpa have been transformec into a peripheral and dependent segment of Westerr culture. Gabriel Chevally, like Tenzing, captures the essence of the relationship:

.... We have brought them a deal of money, but between these people and ourselves a relationship has been clearly established that is something more than a material contract. These men are "engaged" also in the mortal sense of their word, and they bring us not only their muscles, but also their willingness, their pleasure and their participation ... . for deep within them is a taste and an aptitude for exceptional activities. ${ }^{24}$

22 Tenzing, Tiger of the Snows (with assistance from J. R. Ullman), New York, 1955, p. 108.

23 Ibid., p. 108.

24 Dittert, op. cit., pp. 214-215. 